\title{
Preserving Access: A Review of Stroke Thrombectomy during the COVID-19 Pandemic
}

\author{
(D) T.M. Leslie-Mazwi, (D) K.M. Fargen, (D) M. Levitt, (D) C.P. Derdeyn, (D) S.K. Feske, (D) A.B. Patel, and (D).A. Hirsch
}

\begin{abstract}
SUMMARY: Thrombectomy for large-vessel-occlusion stroke is a highly impactful treatment. The spread of coronavirus 19 (COVID19) across the United States and the globe impacts access to this crucial intervention through widespread societal and institutional changes. In this document, we review the implications of COVID-19 on the emergency care of large-vessel occlusion stroke, reviewing specific infection-control recommendations, available literature, existing resources, and expert consensus. As a population, patients with large-vessel occlusion stroke face unique challenges during pandemics. These are broad in scope. Responses to these challenges through adaptation of stroke systems of care and with imaging, thrombectomy, and postprocedural care are detailed. Preservation of access to thrombectomy must be prioritized for its public health impact. While the extent of required changes will vary by region, tiered planning for both escalation and de-escalation of measures must be a part of each practice. In addition, preparations described serve as templates in the event of future pandemics.
\end{abstract}

ABBREVIATIONS: ACE2 = angiotensin-converting enzyme 2; COVID-19 = coronavirus disease 19; ICU = intensive care unit; LVO = large-vessel occlusion; $\mathrm{PPE}=$ personal protective equipment; SARS-CoV-2 = Severe Acute Respiratory Syndrome coronavirus 2

$T$ he Severe Acute Respiratory Syndrome coronavirus 2 (SARS-CoV-2) is documented as entering the human population in Hubei province in China in late 2019. ${ }^{1,2}$ The virus, when symptomatic, causes a predominantly respiratory illness with involvement of other organ systems, labeled coronavirus 2019 (COVID-19). ${ }^{3}$ The infection has spread across the globe. Since the first case in Washington state in January 2020, the disease has been reported in all 50 states and at least 8 jurisdictions. ${ }^{4}$ The infection reached pandemic proportions by March 11, 2020, with sustained risk of further global spread. ${ }^{5}$ At the time of this writing, confirmed cases and mortality continue to rise.
In this document, we review the implications of this pandemic for the emergency care of large-vessel occlusion (LVO) stroke. ${ }^{6}$ Thrombectomy for patients with LVO is one of the most powerful and impactful treatments in the history of medicine. ${ }^{7-9}$ The COVID-19 pandemic threatens access to this crucial intervention. The American Heart Association/American Stroke Association has released temporary emergency guidelines for stroke centers in the United States. ${ }^{10}$ It is anticipated that these will be revised and expanded as available evidence and experience increase. The focus of this article is specifically LVO stroke and its triage and management under these new conditions.

\section{SARS-COV-2 and LVO Stroke}

Knowledge of the effect of SARS-CoV-2 on the cerebrovascular system is limited. The functional receptor for coronaviruses invasion into the human body is the angiotensin-converting enzyme 2 (ACE2), a membrane-bound aminopeptidase highly expressed in cardiac, vascular, and pulmonary tissue. ACE2 appears to play a crucial vascular and immunologic role. ${ }^{11}$ Patients with underlying cardiovascular disease have more severe COVID-19 symptoms, ${ }^{12}$ presumably associated with increased expression of ACE2. SARS-CoV-2 has been identified in postmortem brains, ${ }^{13}$ but direct cerebrovascular effects remain unknown.

In a 1527-patient sample from China, a combined data point of cardiac or cerebrovascular disease was found in $16.4 \%$ of the

1136 Leslie-Mazwi Jul 2020 www.ajnr.org 
total cohort but was 3 times more likely to occur in patients in intensive care settings. ${ }^{14}$ In an article under peer review, $2.3 \%$ of 214 hospitalized patients with COVID-19 (and 4.6\% of 88 severely affected patients) developed acute ischemic stroke during the course of the illness. ${ }^{15}$

COVID-19-induced inflammation, hypoxia, and diffuse intravascular coagulation increase the risk of arterial thromboembolic disease $^{16,17}$ and, therefore, presumably LVO stroke. Other potential mechanisms for arterial stroke in patients with COVID-19 include widespread proinflammatory cytokine responses, atherosclerotic plaque rupture due to local inflammation, hemodynamic changes predisposing to thrombosis or cerebral ischemia, and profound hypoxia. ${ }^{18,19}$ Furthermore, LVO stroke in the COVID19 population may be associated with worse outcomes because of reduced cardiovascular reserve. ${ }^{20}$ The relative contributions of these factors remain to be explored, but early reports may indicate a meaningful rate of cerebrovascular events in patients with COVID-19. ${ }^{15,21,22}$ Indeed, LVO stroke may be a presenting feature of the disease for a subset of patients with COVID-19.

\section{Unique Challenges for the LVO Population during a Pandemic}

Beyond the direct biologic considerations, other unique challenges exist for patients with LVO in the context of the current pandemic. COVID-19 causes the most severe illness in the elderly with underlying cardiovascular and respiratory disease. These are phenotypes shared by many patients presenting with acute ischemic stroke, and comorbidities may represent an insurmountable challenge for the COVID-19-positive LVO population.

Requisite social distancing and self-isolation may cause patients with severe stroke to be less likely to be discovered by family or friends, increasing the time from symptom onset to mobilization of emergency services. Fear of contracting COVID-19 may limit willingness to present to health care. ${ }^{23}$ Additionally, prolonged social distancing or quarantine may produce other consequences because social isolation is a recognized independent risk factor for mortality. ${ }^{24}$

There is a substantial strain on emergency systems during pandemics. Burdening of ambulance transports further contributes to delays. The need for separation also disrupts the team-based approach that underlies the stroke chain of care. Communication, central to treatment decisions, may be more difficult, including with family members who may not be with the patient physically. Patients with stroke are often transferred with fragmented or limited history available, making symptom detection for respiratory disease unreliable.

Transfers typically occur under conditions of intense time pressure, with disability at stake for patients and risk of infection for providers. Patients with LVO transferred from centers to which they initially present to centers that provide thrombectomy carry the risk of spreading infection. The steps necessary for appropriate precautions mean that time metrics for quality-ofcare initiatives and certification purposes will likely be impaired.

Finally, the LVO stroke population has broad intensive care needs and often a prolonged need for institutionalization (hospitals or rehabilitation centers). Demand for personal protective equipment (PPE), ventilators, intensive care unit (ICU) beds, and other hospital resources by patients with COVID-19 may disrupt the capacity to provide the high level of care required by the LVO population. These varied considerations are particularly important as treatment rates for LVO continue to increase, with thrombectomy occurring more than every other day at many centers. ${ }^{25}$

\section{Guiding Principles for the Pandemic Response}

Given this background, certain principles must guide the collective response to all aspects of care of patients with LVO stroke during the COVID-19 pandemic:

1. We must find the appropriate balance between patient access and outcomes and the necessary compromises for provider and patient safety. Attempting to maintain historic metrics despite the multiple new considerations of COVID-19 places our health care providers at risk. However, protecting access to the remarkably potent therapeutic effect of thrombectomy is an imperative. Questions concerning which compromises are acceptable, effective, or appropriate remain open.

2. We must anticipate a rapid pace of change. In response to shifting data, recommended approaches change regularly. Therefore, stroke services must remain nimble and stay in communication with each other and hospital, regional, and national leadership. Frequent review of protocols is necessary, with clear lines of dissemination of changes.

3. We must strive for collaborative, noncompetitive, multidisciplinary interactions. The impact of this pandemic crosses specialty lines. It is essential that adequate exchange of information be available to identify emerging trends and therapeutic targets in the pandemic. Considerations of nationality, influence, reimbursement, and practice scope must be superseded by the need for collective action and information. Lessons learned in other practice environments already affected by the disease (China, Italy, ${ }^{26}$ Singapore, ${ }^{27}$ Spain, and elsewhere) can be applied to decisions made in emerging pandemic epicenters.

These principles apply to all areas of LVO care.

\section{Considerations for Stroke Systems of Care}

COVID-19 will necessitate many changes in stroke care systems. Stroke networks must take charge of these changes to achieve the following goals: to provide unbroken access for patients to thrombectomy during the COVID-19 pandemic, distribute patients to open centers, minimize the time that referring hospitals spend searching for an accepting center, and simplify organization and communication. Meeting these goals will need to occur in the context of increasing resource use in the treatment of patients affected by the COVID-19 pandemic, which has already strained emergency department, ICU, anesthesia, and operating room resources.

Elective cases and clinics progressively have to be deferred to comply with social distancing and to conserve ICU capacity, ventilators, staff, and PPE for burgeoning COVID-19 caseloads. Decisions will be individualized on the basis of local conditions, but many US practices have already enacted these measures in regions where COVID-19 cases are escalating rapidly. 
Messaging to patients should be clear, and a process instituted to ensure that once normalcy returns, patients can be rescheduled. In the early stages of the pandemic, case priority strata may be formed (for example, interventions over diagnostic angiograms), but as the pandemic gains increasing ground, all nonemergent procedures may need to be cancelled. As much as possible, thrombectomy for LVO should be protected from this withdrawal of services. Given the extraordinarily low number needed to treat and the risk of severe disability or death, coupled with the time sensitivity of the condition, thrombectomy should remain a protected and available treatment option. If system stress due to COVID-19 is extreme, criteria may need to be established for patient-treatment selection, with diminishing indications for thrombectomy procedures. For example, patients with medium vessel occlusions, large ischemic cores or very-late-window presentations may no longer be offered thrombectomy if the pandemic has a drastic local effect.

Health care workers are at risk of contracting the virus. ${ }^{28}$ Institutional protocols must be reviewed to incorporate isolation procedures for the care of patients with LVO. Rarely will a patient be transferred for thrombectomy with a known COVID-19 disease status; more typically, a patient's COVID-19 status will be unknown with variable levels of suspicion. Furthermore, absence of patient symptoms cannot provide complete reassurance because this does not ensure lack of infection or inability to transmit the virus. ${ }^{29,30}$ Screening of transfer patients or emergency department admissions for COVID-19 risk should be undertaken. Screens should include symptoms (including nonrespiratory), ${ }^{31}$ history of exposure to possible infected individuals or high-risk professions, travel or geographic areas, and any recent COVID-19 testing with results.

Protective staff measures must include PPE for any exposure to a patient considered a potential COVID-19 case. Essential PPE includes, currently, at a minimum, gown, gloves, goggles (or face shields), and (depending on the degree of potential exposure) a surgical mask or either an N-95 mask or Powered Air-Purifying Respirators (PAPRs). The goal is prevention of viral particles contacting mucous membranes. As local infection rates intensify, COVID-19 staff may be required to take PPE precautions from emergency department arrival irrespective of symptom checklists for all presenting patients. This approach was applied in regions of Wuhan and Lombardy during the peak of the pandemic there. ${ }^{32}$ Training staff on proper PPE donning and doffing techniques must be provided and documented. Symptom awareness and monitoring must extend across the entire care spectrum. Some centers are currently requiring all clinical staff to self-attest at the beginning of each shift to being COVID-19-symptom-free. A culture of nonstigmatized self-quarantine when infectious symptoms are present should be cultivated, and all providers should have access to testing.

In the face of COVID-19, staffing models will need to evolve. As infection becomes ubiquitous throughout health care systems, many staff will become secondarily infected and require treatment or will have to self-quarantine due to exposure history. This scenario poses challenges because at baseline, many hospitals run on limited staffing models. A 2019 survey of neurointerventional physicians revealed that $50 \%$ of physicians take mechanical thrombectomy calls daily or every second day. ${ }^{33}$ The situation is similar for neurointerventional nurses and radiology technologists; in a recent study from 20 stroke centers in the United States, less than half had call pools for stroke that exceeded 6 total nurses or technologists. ${ }^{34}$ Hospitals, due to these limited teams, are, therefore, susceptible to severe disruption by viral infection or furloughs for staff exposure.

Effort to reduce simultaneous exposure must therefore be intensified. Any meetings among stroke providers (neurointerventional or otherwise) should be held virtually, including teaching sessions in academic settings, to prevent the risk of inadvertent exposure. In the most extreme versions of such social distancing regimens, no members of the neurointerventional team are routinely present at the hospital at all but remain available for emergencies only, including conducting all consults remotely. As the volume of infected personnel increases, many stroke service components will need to operate with minimal staffing of a few noninfected or previously infected but now recovered team members. If infection breaches a critical threshold, some emergency LVO services (including even ambulance transport) may not be possible at all. Call schedules need to be constructed with increased reserve to account for the possibility of losing members of a team during self-isolation periods.

Care systems must decide on emergency medical service protocols and sequential routing policies for patients with LVO to thrombectomy-capable centers if capacity is exceeded at 1 facility. In Lombardy, all catheter interventions were localized to a handful of sites, given the strain the rest of the region experienced from the needs of patients with COVID-19. For acute cardiac interventions, a total of 13 hubs were selected of 55 capable hospitals. These designated "hubs" accepted patients transferred from corresponding "spokes," 32 allowing resources to be condensed and therefore consistently available for catheter-based interventions. Engagement of emergency medical service is a key piece of this routing effort to coordinate available thrombectomy for a region. Additionally, referring hospitals must be aware that thrombectomy services are continuing and of any routing policies if these are required. Hospital leadership at thrombectomy-capable centers should provide assurance that beds will remain available for such emergencies. Furthermore, insurance providers will need flexibility for out-of-network care, for example in the form of prearranged COVID-19 waivers.

Care systems will likely see a slowing of LVO care. Time metrics (door-to-CT, door-to-reperfusion, and so forth) may be dramatically affected due to slower stroke identification in the field, overburdened emergency departments, and difficulties in timely hospital transfers. Delays were observed in cardiac catheterization procedures in Hong Kong during the disease peak, primarily related to longer times from symptom onset to first medical contact and increased PPE requirements. ${ }^{35}$ These delays must be acknowledged by certifying organizations as an unavoidable consequence of care under the current conditions.

Finally, sharing of best practices between centers allows combined flexibility of thought and planning to meet the rapid pace of adaptation in pandemics. This may be formalized into weekly virtual meetings among thrombectomy-capable centers or informally among looser networks of providers. In New 
England, for example, the 8 thrombectomy-capable centers in Massachusetts and the centers in the neighboring states (Maine, New Hampshire, Vermont, Rhode Island, and Connecticut) have held a weekly virtual meeting during the pandemic to discuss and compare approaches and centralized information about the capacity to take patients for thrombectomy. This provides statewide coordination. Careful collection of data throughout, using Get With the Guidelines-Stroke (https://www.heart.org/en/professional/quality-improvement/ get-with-the-guidelines/get-with-the-guidelines-stroke) or other platforms, will ensure the retrospective opportunity to assess the impact of emergency measures.

\section{Considerations for Stroke Imaging}

Radiology technologists and other staff will encounter patients with LVO stroke early in the course of their evaluation, possibly before full vetting of the COVID-19 risk has occurred. The lowest number of staff necessary to transport patients to the scanner, move them onto the CT or MR imaging table, perform imaging, and then transport them to the next therapeutic destination should be the goal. Universal PPE use may be required in later stages of the pandemic, but symptom-triggered precautions are likely acceptable early on.

The role of adding CT chest imaging to scanning for patients presenting with stroke symptoms is yet to be validated, though CT findings are sensitive to COVID-19. ${ }^{36,37}$ While this is currently not formally recommended in LVO evaluation, it has been applied in certain highly endemic areas. However, patients may become symptomatic later in their disease course, so if applied, this should not provide a false sense of reassurance in endemic areas.

Those who perform scanner cleaning after imaging patients at high risk of COVID-19 must account for the possibility of prolonged virus persistence on surfaces. ${ }^{38}$ In centers with multiple scanners, there may be a logistic benefit to the designation of "clean" and "dirty" scanners for localizing PPE supplies, cleaning supplies, and other components of pandemic response. This may impact stroke workflow.

Finally, delays may be incurred in the interpretation of imaging depending on the location of the radiologist. For reads performed remotely in either a reading room or from a remote location outside the hospital, data transfers may delay radiologist response times. This delay may be less of a concern for centers with automated imaging interpretation, ${ }^{39}$ but data under current pandemic conditions are not available for verification.

\section{Considerations for Thrombectomy Procedures}

While procedural fundamentals are unchanged, there are various considerations for the actual procedural aspects of LVO care during the COVID-19 pandemic. The concept of a protected code stroke algorithm has been recently introduced to the literature, ${ }^{40}$ reflecting the combined goal of emergent service provision and protection of service providers.

Consent for cases cannot occur in person because of remotely positioned teams and the need for social distancing. Dual attending consent (neurology and neurointerventional attending consensus) offers an option when family members cannot be contacted, given that thrombectomy is the recommended standard of care. Witnessed telephone consent in conference call format for patients with indications outside the prescribed guidelines should be pursued. Family updates by telephone or video will keep relatives informed of treatment decisions and disease course. In areas dealing with a large volume of patients with COVID-19, hospital visitors may not be allowed at all, and telephone or video contact represents the link between family and the care system. Virtual connections can also be established at the procedural suite to allow non-neurointerventional members of the care team to participate in collaborative case decisions without their physical presence.

Procedural PPE use should be equivalent for all members of the care team (anesthesia, nursing, proceduralists, technologists, and so forth), and the number of staff members in a room should be strictly minimized. COVID-19 status and the PPE application process should be reviewed as part of the preprocedural case discussion with the care team (huddle). Caution should be taken with potential in-room exposures, including opening of cabinets for equipment. Equipment should be removed from storage cabinets if these are in the procedure room and placed in an accessible location that is not at risk of contamination.

Sedation choices for thrombectomy present challenges in the midst of a respiratory pandemic. Currently practice varies for the use of general anesthesia or conscious sedation during these cases. Limited published data are available at this time to guide decisions. ${ }^{41,42}$ Intubation carries the appeal of a closed respiratory circuit, in theory exposing the staff caring for the patient to less viral load. However, bag-mask ventilation and intubation itself are highly aerosol-generating procedures. If required, all aerosolgenerating procedures should ideally be accomplished in a negative pressure environment. The minimum number of staff required for intubation should be in attendance in full PPE. Beyond the use of video laryngoscopy to protect anesthesia staff, innovative modifications of the intubation technique are being explored. ${ }^{43}$ With intubation and a closed respiratory circuit, the load of viral particles in the environment is reduced. However, any breach in the respiratory circuit (tube disconnections during transfer of the patient to the procedural table from the stretcher, suctioning, unrecognized cuff leak, or ventilator change) risks an exposure to individuals who may be falsely reassured by the patient's intubated status. Use of conscious sedation when possible avoids this intense aerosolization. The utility of a mask worn by a patient with suspected or confirmed COVID- $19^{40}$ (as well as PPE for providers) depends on the status of the patient's airway. If there is concern for airway patency or vomiting, then patient masks should be avoided. Irrespective of the individual approach to procedural sedation, all participants in mechanical thrombectomy must be well-versed in the use of PPE and appropriate precautions, including the proper techniques for donning and doffing.

Procedural sedation choices have implications beyond thrombectomy. Current recommendations for intubated patients are to avoid extubating in the angiography suite (unless the suite is a negative pressure environment). ${ }^{44}$ Intubated patients require ventilators for both transport and care in the ICU. Conscious sedation potentially avoids occupying a ventilator (and therefore 
an ICU bed) should a shortage exist. These airway considerations were reinforced in a recent release from the Society of Neurointerventional Surgery. ${ }^{44,45}$ Local practice conditions will heavily influence decisions about sedation management for patients with LVO.

\section{Postprocedural Considerations}

Postprocedure, the patient's destination can be determined by the nature of the case and the condition of the patient. Typically, ICU care is required, but patients who are doing well may be considered for observation in postoperative units before admission to a floor if ICU beds are limited or unavailable. ${ }^{44}$ In addition to the typical stroke work-up, COVID-19 testing should be performed on all patients with stroke and prioritized because of implications for procedures such as swallowing evaluations and diagnostic work-up, as well as rehabilitation placement. This will assist with bed availability by ensuring more expeditious hospital throughput.

\section{Other Aspects of Thrombectomy during This Pandemic}

Other components of this pandemic are important to acknowledge as they relate to thrombectomy. Family stress is high for all team members, with the unique situation of possible quarantine from family either at home or in an off-site location removed from the home, which increases isolation and anxiety. ${ }^{46,47}$ Family and friends of team members will also experience stress related to the changes required during these times. Strategies should be shared for minimizing home exposures, including a defined inhome doffing area, laundry, showering after arrival home, and other measures that may be helpful in decreasing the risk of spread.

Empathy for colleagues is essential, including awareness of mental health stress. The possibility of extended time on-call increases the risk of mental health issues and poor clinical performance. ${ }^{48}$ Team communication with clarity and immediacy will aid in maintaining morale. Cross-coverage between different role groups if furloughs for health become extensive should be expected. Finally, reimbursement and call coverage costs for care teams will be impaired in the larger context of the massive economic implications of the pandemic. Hospital leadership will be expected to address these concerns for the teams on the front lines of the pandemic battle.

\section{CONCLUSIONS}

Thrombectomy for selected patients with acute ischemic stroke and LVO has a magnitude of benefit that exceeds almost any other time-critical intervention. ${ }^{49}$ Access to thrombectomy must be maintained in the face of the current pandemic. This article outlines options to be considered. Tiered planning for both escalation and de-escalation of protective measures must be a part of each practice. As the pandemic gradually ebbs, the measures instituted can be peeled back in reverse order to allow a measured return to full capacity. The extent and magnitude of the changes required are not yet clear. In addition, preparations as described here should serve as templates to prepare us better for the next pandemic. $^{50,51}$ By considering these issues in our pandemic response, we create a more resilient overall system of care for patients with LVO stroke everywhere.

Disclosures: Michael Levitt-UNRELATED: Consultancy: Minnetronix Inc; Grants/ Grants Pending: Stryker, Covidien, Volcano Corp, Philips Healthcare, Comments: unrestricted educational and equipment grants*; Stock/Stock Options: eLoupes, Synchrotron, Cerebrotech. Colin P. Derdeyn—UNRELATED: Consultancy: Penumbra, Genae, NoNo Inc, Comments: Data and Safety Monitoring Board member for these industry-sponsored clinical trials*; Employment: University of lowa Hospitals and Clinics.* Steven K. Feske-UNRELATED: Grants/Grants Pending: Biogen, Comments: Biogen sponsors the CHARM trial.* Aman B. Patel—UNRELATED: Consultancy: Penumbra, MicroVention, Medtronic, Comments: consultant, proctoring. Joshua A. Hirsch—UNRELATED: Consultancy: Medtronic, Relievant Medsystems, InNeuroCo; Grants/Grants Pending: Harvey L. Neiman Health Policy Institute. *Money paid to the institution.

\section{REFERENCES}

1. Wang D, Hu B, Hu C, et al. Clinical characteristics of $\mathbf{1 3 8}$ hospitalized patients with 2019 novel coronavirus-infected pneumonia in Wuhan, China. JAMA 2020 Feb 7. [Epub ahead of print] CrossRef Medline

2. Zhou P, Yang XL, Wang XG, et al. A pneumonia outbreak associated with a new coronavirus of probable bat origin. Nature 2020;579:270-73 CrossRef Medline

3. Paules CI, Marston HD, Fauci AS. Coronavirus infections: more than just the common cold. JAMA 2020 Jan 23. [Epub ahead of print] CrossRef Medline

4. Prevention CfDCa. Coronavirus 2019 2020. https://www.cdc.gov/ coronavirus/2019-ncov/cases-updates/cases-in-us.html. Accessed April 1,2020

5. World Health Organization. Coronavirus Disease (COVID-19) Pandemic. May 4, 2020. https://www.who.int/emergencies/diseases/ novel-coronavirus-2019. Accessed March 31, 2020

6. Leslie-Mazwi T, Chandra RV, Baxter BW, et al; Society of NeuroInterventional Surgery. ELVO: an operational definition. $J$ Neurointerv Surg 2018;10:507-09 CrossRef Medline

7. Goyal M, Menon BK, van Zwam WH, et al; HERMES collaborators. Endovascular thrombectomy after large-vessel ischaemic stroke: a meta-analysis of individual patient data from five randomised trials. Lancet 2016;387:1723-31 CrossRef Medline

8. Albers GW, Marks MP, Kemp S, et al; DEFUSE 3 Investigators. Thrombectomy for stroke at $\mathbf{6}$ to 16 hours with selection by perfusion imaging. N Engl J Med 2018;378:708-18 CrossRef Medline

9. Nogueira RG, Jadhav AP, Haussen DC, et al; DAWN Trial Investigators. Thrombectomy 6 to 24 hours after stroke with a mismatch between deficit and infarct. $N$ Engl J Med 2018;378:11-21 CrossRef Medline

10. Temporary emergency guidance to US stroke centers during the COVID-19 pandemic. Stroke 2020 Apr 1. [Epub ahead of print] CrossRef Medline

11. Turner AJ, Hiscox JA, Hooper NM. ACE2: from vasopeptidase to SARS virus receptor. Trends Pharmacol Sci 2004;25:291-94 CrossRef Medline

12. Zheng YY, Ma YT, Zhang JY, et al. COVID-19 and the cardiovascular system. Nat Rev Cardiol 2020;17:259-60 CrossRef Medline

13. Li YC, Bai WZ, Hashikawa T. The neuroinvasive potential of SARSCoV2 may play a role in the respiratory failure of COVID-19 patients. J Med Virol 2020 Feb 27. [Epub ahead of print] CrossRef Medline

14. Li B, Yang J, Zhao F, et al. Prevalence and impact of cardiovascular metabolic diseases on COVID-19 in China. Clin Res Cardiol 2020; 109:531-38 CrossRef Medline

15. Mao L, Wang M, Chen S, et al. Neurological Manifestations of Hospitalized Patients with COVID-19 in Wuhan, China: a retrospective case series study. MedRxiv Feb 25, 2020. https://www. medrxiv.org/content/10.1101/2020.02.22.20026500v1. Accessed March 31, 2020 
16. Klok FA, Kruip M, van der Meer NJM, et al. Incidence of thrombotic complications in critically ill ICU patients with COVID-19. Thromb Res 2020 Apr 10. [Epub ahead of print] CrossRef Medline

17. Lillicrap D. Disseminated intravascular coagulation in patients with 2019-nCoV pneumonia. J Thromb Haemost 2020;18:786-87 CrossRef Medline

18. Smeeth L, Thomas SL, Hall AJ, et al. Risk of myocardial infarction and stroke after acute infection or vaccination. N Engl J Med 2004; 351:2611-18 CrossRef Medline

19. Mehta P, McAuley DF, Brown M, et al; HLH Across Specialty Collaboration, UK. COVID-19: consider cytokine storm syndromes and immunosuppression. Lancet 2020;395:1033-34 CrossRef Medline

20. Driggin E, Madhavan MV, Bikdeli B, et al. Cardiovascular considerations for patients, health care workers, and health systems during the coronavirus disease 2019 (COVID-19) pandemic. J Am Coll Cardiol 2020 Mar 18. [Epub ahead of print] CrossRef Medline

21. Talen J. COVID-19: Neurologists in Italy to Colleagues in US: Look for Poorly-Defined Neurologic Conditions in Patients with the Coronavirus. Neurology Today March 27, 2020. https://journals. lww.com/neurotodayonline/blog/breakingnews/pages/post.aspx? PostID=920. Accessed March 31, 2020

22. Oxley TJ, Mocco J, Majidi S, et al. Large-vessel stroke as a presenting feature of Covid-19 in the young. N Engl J Med 2020 Apr 28. [Epub ahead of print] CrossRef Medline

23. Thornton J. Stroke: "striking reductions" are seen in number of people with symptoms seeking help. BMJ 2020;369:m1406 CrossRef Medline

24. Holt-Lunstad J, Smith TB, Layton JB. Social relationships and mortality risk: a meta-analytic review. PLoS Med 2010;7:e1000316 CrossRef Medline

25. Williams MM, Leslie-Mazwi T, Hirsch JA, et al. Real-world effects of late window neurothrombectomy: procedure rates increase without night-time bias. J Neurointerv Surg 2020;12:460-64 CrossRef Medline

26. Grasselli G, Pesenti A, Cecconi M. Critical care utilization for the COVID-19 outbreak in Lombardy, Italy: early experience and forecast during an emergency response. JAMA 2020 Mar 13. [Epub ahead of print] CrossRef Medline

27. Wong JEL, Leo YS, Tan CC. COVID-19 in Singapore: current experience: critical global issues that require attention and action. JAMA 2020 Feb 20. [Epub ahead of print] CrossRef Medline

28. Ran L, Chen X, Wang Y, et al. Risk factors of healthcare workers with corona virus disease 2019: a retrospective cohort study in a designated hospital of Wuhan in China. Clin Infect Dis 2020 Mar 17. [Epub ahead of print] CrossRef Medline

29. Chang D, Xu H, Rebaza A, et al. Protecting health-care workers from subclinical coronavirus infection. Lancet Respir Med 2020;8: e13 CrossRef Medline

30. Lauer SA, Grantz KH, Bi Q, et al. The incubation period of coronavirus disease 2019 (COVID-19) From publicly reported confirmed cases: estimation and application. Ann Intern Med 2020 Mar 10. [Epub ahead of print] CrossRef Medline

31. Pan L, Mu M, Yang P, et al. Clinical characteristics of COVID-19 patients with digestive symptoms in Hubei, China: a descriptive, cross-sectional, multicenter study. Am J Gastroenterol 2020;115: 766-73 CrossRef Medline

32. Stefanini GG, Azzolini E, Condorelli G. Critical organizational issues for cardiologists in the COVID-19 outbreak: a frontline experience from Milan, Italy. Circulation 2020 Mar 24. [Epub ahead of print] CrossRef Medline

33. Fargen KM, Arthur AS, Leslie-Mazwi T, et al. A survey of burnout and professional satisfaction among United States neurointerventionalists. J Neurointerv Surg 2019;11:1100-04 CrossRef Medline
34. Fargen KM, Ansari SA, Spiotta A, et al. Influence of thrombectomy volume on non-physician staff burnout and attrition in neurointerventional teams. J Neurointerv Surg 2020 Apr 3. [Epub ahead of print] CrossRef Medline

35. Tam CF, Cheung KS, Lam S, et al. Impact of coronavirus disease 2019 (COVID-19) outbreak on ST-segment-elevation myocardial infarction care in Hong Kong, China. Circ Cardiovasc Qual Outcomes 2020;13:e006631 CrossRef Medline

36. Fang Y, Zhang H, Xie J, et al. Sensitivity of chest CT for COVID-19: comparison to RT-PCR. Radiology 2020 Feb 19. [Epub ahead of print] CrossRef Medline

37. Ai T, Yang Z, Hou H, et al. Correlation of chest CT and RT-PCR testing in coronavirus disease 2019 (COVID-19) in China: a report of 1014 cases. Radiology 2020 Feb 26. [Epub ahead of print] CrossRef Medline

38. Kampf G, Todt D, Pfaender S, et al. Persistence of coronaviruses on inanimate surfaces and their inactivation with biocidal agents. $J$ Hosp Infect 2020;104:246-51 CrossRef Medline

39. Vagal A, Wintermark M, Nael K, et al. Automated CT perfusion imaging for acute ischemic stroke: pearls and pitfalls for realworld use. Neurology 2019;93:888-98 CrossRef Medline

40. Khosravani H, Rajendram P, Notario L, et al. Protected code stroke: hyperacute stroke management during the coronavirus disease 2019 (COVI D-19) pandemic. Stroke 2020 Apr 1. [Epub ahead of print] CrossRef Medline

41. Cheung JC, Ho LT, Cheng JV, et al. Staff safety during emergency airway management for COVID-19 in Hong Kong. Lancet Respir Med 2020;8:e19 CrossRef Medline

42. Sharma D, Rasmussen M, Han R, et al. Anesthetic Management of Endovascular Treatment of Acute Ischemic Stroke During COVID19 Pandemic: Consensus Statement from Society for Neuroscience in Anesthesiology \& Critical Care (SNACC), endorsed by Society of Vascular \& Interventional Neurology (SVIN), Society of NeuroInterventional Surgery (SNIS), Neurocritical Care Society (NCS), and European Society of Minimally Invasive Neurological Therapy (ESMINT). J Neurosurg Anesthesiol 2020 Apr 8. [Epub ahead of print] CrossRef Medline

43. Canelli R, Connor CW, Gonzalez M, et al. Barrier enclosure during endotracheal intubation. $N$ Engl J Med 2020 Apr 3. [Epub ahead of print] CrossRef Medline

44. Fraser JF, Arthur AS, Chen M, et al. Society of NeuroInterventional Surgery recommendations for the care of emergent neurointerventional patients in the setting of covid-19. J Neurointerv Surg 2020 Apr 15. [Epub ahead of print] CrossRef Medline

45. Society of Neurointervantional Surgery. Care Recommendations for Emergent Neurointerventional Patients in the Setting of COVID. March 28, 2020. Accessed March 31, 2020

46. Chen Q, Liang M, Li Y, et al. Mental health care for medical staff in China during the COVID-19 outbreak. Lancet Psychiatry 2020;7: e15-16 CrossRef Medline

47. Greenberg N, Docherty M, Gnanapragasam S, et al. Managing mental health challenges faced by healthcare workers during covid-19 pandemic. BMJ 2020;368:m1211 CrossRef Medline

48. Pilcher JJ, Huffcutt AI. Effects of sleep deprivation on performance: a meta-analysis. Sleep 1996;19:318-26 CrossRef Medline

49. Martinez-Gutierrez JC, Leslie-Mazwi T, Chandra RV, et al. Number needed to treat: a primer for neurointerventionalists. Interv Neuroradiol 2019;25:613-18 CrossRef Medline

50. Bloom DE, Cadarette D. Infectious disease threats in the twentyfirst century: strengthening the global response. Front Immunol 2019;10:549 CrossRef Medline

51. Gates B. Innovation for pandemics. N Engl J Med 2018;378:2057-60 CrossRef Medline 